\title{
Change of Spectroscopic Properties of PU/PVC Doped by Single Walled Carbon Nanotubes
}

\author{
L. H. Gaabour \\ Physics Department, Faculty of Science, Alfaisaliah Campus, King Abdulaziz University, Jeddah, KSA \\ Email: ljaabour@kau.edu.sa
}

How to cite this paper: Gaabour, L.H. (2016) Change of Spectroscopic Properties of PU/PVC Doped by Single Walled Carbon Nanotubes. Optics and Photonics Journal, 6, 305-314.

http://dx.doi.org/10.4236/opj.2016.612031

Received: November 23, 2016

Accepted: December 18, 2016

Published: December 21, 2016

Copyright $\odot 2016$ by author and Scientific Research Publishing Inc. This work is licensed under the Creative Commons Attribution International License (CC BY 4.0).

http://creativecommons.org/licenses/by/4.0/

\begin{abstract}
Nanocomposite films based on polyurethane and polyvinyl chloride (PU/PVC) doped by low content $(\leq 0.045 \mathrm{wt} \%)$ of single wall carbon nanotubes (SWCNTs) were prepared and characterized. The structural, optical, thermal and mechanical properties of the prepared nanocomposites were characterized by various tools. The IR band at $3437 \mathrm{~cm}^{-1}$ in SWCNTs vanishing for doped samples signified that SWCNTs were successfully covalently encapsulated with PU/PVC. The X-ray peaks broaden with reduced intensity which refers to a reduction of the crystallinity for the blend after increase of SWCNTs attributed to changing in the crosslink density. UV/Vis analysis reveals that the optical band gap values were decreased with increased SWCNT attributed to the formation of defects in polymeric matrix with increase in the degree of disorder in the films. These defects produce the localized states in the optical band gap. All results data showed well dispersion of SWCNTs in polymer matrix at all weight percentages and an interaction between SWCNTs and the blend occurred. The thermal analysis showed that the melting point $\left(\mathrm{T}_{\mathrm{m}}\right)$ and degradation temperature $\left(\mathrm{T}_{\mathrm{d}}\right)$ of the obtained films were increased gradually with adding of SWCNTs. Furthermore, the thermal stability was improved after adding SWCNTs into the PU/PVC polymer blend.
\end{abstract}

\section{Keywords}

Nanocomposites, SWCNTs, X-Ray, TGA, Mechanical Properties

\section{Introduction}

Polyurethane (PU) has attracted an exceptional measure of consideration because of a variety of applications such as thermoplastic, elastomers, scientific device, textiles and smart actuators adhesive [1]. The molecular structure of PU can be easily tailored to meet particular property requirements. 
Poly vinyl chloride (PVC) is a polymer utilized as often as possible as a part of uses that require structural features (mechanical strength) abilities. Since PVC has attractive properties, it usually requires the incorporation of different additives [2] [3].

Blending PU with other polymers has been of a considerable interest in recent years. There are many studies on the blends of PVC with PU [4] [5]. The presence of intermolecular bonding of hydrogen between carbonyl groups $(\mathrm{C}=\mathrm{O})$ of $\mathrm{PU}$ with active $\alpha$-hydrogen in PVC chains makes PVC component and PU more compatible in the main blend chain [6]. Adding PVC to PU would be possible to expand the characteristics of two polymers to obtain compatibility of the blends and better mechanical property. Due to well dispersion, highly potential nanoparticles, or tubes in polymeric matrices, high-performance lightweight nanocomposites can be produced [7].

Carbon nanotubes (CNTs) incorporating into the polymeric matrices is an attractive method to combine the optical, electrical and mechanical properties for CNTs with the advantages of the polymer [8] [9]. It has attracted numerous researchers because of their good properties. As a result of the properties with nanometer scale size and aspect ratio, they are seen perfect as a strong reinforcing specialist for high strength polymer nanocomposites.

Many researchers have focused on the preparation of polymer nanocomposites loaded with carbon nanotubes by casting technique, mixed by melt method and electro spinning with enhanced thermal and mechanical structure [10] [11] [12]. The present work seeks for synthesis and investigation of PU/PVC polymer blend doped with low content of single-walled carbon nanotubes $(\leq 0.045 \mathrm{wt} \%)$ and studies the changes of the structural and spectroscopic properties of the nanocomposites.

\section{Experimental Work}

Polyurethane (PU) have $\mathrm{M}_{\mathrm{w}} \approx 330,600$ from Cargill-Dow Company, South Korea and high molecular weight polyvinyl chloride (PVC) supplied by Fluka. Tetra hydro furan (THF) supplied from Duksan Company (Korea) and it is used as received. Purified single walled carbon nanotubes (SWCNTs) with $\mathrm{COOH}$ functional groups (NTX10) were obtained from Nanothinx, Greece. SWCNTs- $\mathrm{COOH}$ has a diameter of $8-14 \mathrm{~nm}$, length $\geq 5 \mu \mathrm{m}$ and a purity of $88 \%$.

The PU/PVC (75:25) wt\% blend composite was dissolved in Tetrahydrofuran (THF) as a solvent at $45^{\circ} \mathrm{C}$ under stirring until 24 hour to complete dissolution to form a homogeneous solution. The polymer blend solution was left without stirring at $30^{\circ} \mathrm{C} \cong 2$ hour to remove the bubbles during stirring. Also, SWCNT functionalization was mixed with polymer solution under continuous stirring in an ultrasonic to disperse of these CNTs inside the solution. Different concentration of SWCNT $(0.015,0.030$ and 0.045 wt\%) were added. After that, the films of the (PU/PVC)-SWCNT were obtained. The nanocomposites solution was put in oven at room temperature to evaporate the solvent for about $36 \mathrm{~h}$. The obtained films were kept in vacuum desiccators before their investigation and measurement.

The FT-IR absorption spectra were carried out using the single beam Fourier trans- 
form-infrared spectrometer (FT-IR-430, JASCO, Japan). The FT-IR spectra of the samples were obtained in the spectral range of $2000-400 \mathrm{~cm}^{-1}$. The X-Ray diffraction scans were obtained using DIANO corporation-USA equipped using $\mathrm{Cu}-\mathrm{K} \alpha$ radiation $(\lambda=$ $1.540 \AA$, at $30 \mathrm{kV}$, the Bragg angle $2 \theta=5^{\circ}-60^{\circ}$. The UV-vis. spectra were measured in wavelength region of $190-900 \mathrm{~nm}$ by spectrophotometer (V-570 UV-VIS-NIR, JASCO, Japan). Thermogravimetric analysis (TGA) used to characterize the decomposition and thermal stability of prepared samples was carried out using A Perkin-Elmer TGA-7 from $30^{\circ} \mathrm{C}$ to $550^{\circ} \mathrm{C}$ with a heating rate of $5^{\circ} \mathrm{C} / \mathrm{min}$.

\section{Results and Discussion}

\subsection{Fourier Transform Infrared (FT-IR)}

Figure 1 displays FT-IR spectrum of both polyurethane (PU) and poly vinyl chloride (PVC). The spectrum of PU shows IR absorption bands at $3340 \mathrm{~cm}^{-1}$ due to $\mathrm{NH}$ stretching, at $2950 \mathrm{~cm}^{-1}$ corresponding to $\mathrm{CH}$ asymmetric stretching, the band at $2860 \mathrm{~cm}^{-1}$ due to $\mathrm{CH}$ symmetric stretching, $1730 \mathrm{~cm}^{-1}$ for $\mathrm{C}=\mathrm{O}$ stretching of urethane groups, $1602 \mathrm{~cm}^{-1}$ due to $\mathrm{NH}$ bonding), $1530 \mathrm{~cm}^{-1}$ attributed to $\mathrm{C}-\mathrm{C}$ stretching (aromatic)) and at $1065 \mathrm{~cm}^{-1} \mathrm{C}-\mathrm{O}$ assigned to stretching of urethane groups [13] [14]. The spectrum of pure PVC shows the main characteristic bands at $2960 \mathrm{~cm}^{-1}$ due to $\mathrm{CH}$ stretching, 2910 $\mathrm{cm}^{-1}$ assigned to $\mathrm{CH}_{2}$ asymmetric stretching, $2861 \mathrm{~cm}^{-1}, 1434 \mathrm{~cm}^{-1}$ due to $\mathrm{CH}$ bending and at $837 \mathrm{~cm}^{-1}$ attributing to $\mathrm{C}-\mathrm{Cl}$ stretching [15] [16].

The spectrum for PU/PVC blend shows characteristic absorption bands of both PU and. However, the band corresponding to $\mathrm{C}-\mathrm{N}-\mathrm{H}$ bonding vibrations modes at 1602 $\mathrm{cm}^{-1}$ and $837 \mathrm{~cm}^{-1}$ were slightly shift to $1594 \mathrm{~cm}^{-1}$ and $817 \mathrm{~cm}^{-1}$ assigned to hydrogen bonded interactions between $\mathrm{C}-\mathrm{N}-\mathrm{H}$ in $\mathrm{PU}$ and $\mathrm{C}-\mathrm{Cl}$ in PVC groups. The shift of IR absorption band can be used as measure intermolecular interactions between two polymers.

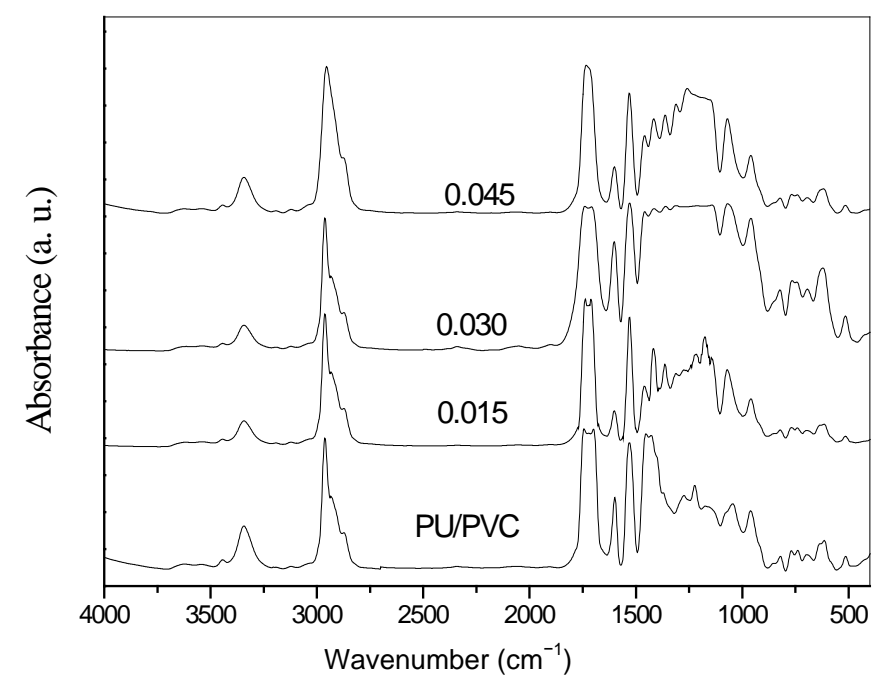

Figure 1. FT-IR spectra of pure PU, pure PVC and pure PU/PVC. 
It know that, pure single walled carbon nanotubes have function group at $3437 \mathrm{~cm}^{-1}$ refers to $\mathrm{OH}$ stretching of the hydroxyl group which can be attributed to the oscillation of carboxyl groups $(\mathrm{O}=\mathrm{C}-\mathrm{OH}$ and $\mathrm{C}-\mathrm{OH})$. The main band which observed at $2922 \mathrm{~cm}^{-1}$ is attributed to asymmetric stretching of $\mathrm{CH}_{2}$ and at $2861 \mathrm{~cm}^{-1}$ is attributed to symmetric stretching of $\mathrm{CH}_{2}$. The absorption band at $1735 \mathrm{~cm}^{-1}$ is corresponding to $\mathrm{C}=\mathrm{O}$ stretching of $\mathrm{COOH}$. The band at $1630 \mathrm{~cm}^{-1}$ can be associated with the stretching of the CNTs backbone and band at $1579 \mathrm{~cm}^{-1}$ is $\mathrm{C}=\mathrm{C}$ vibration .

Figure 2 depicts the FT-IR spectra of PU/PVC doped with low contents of SWCNT. It can be seen that, the intensity of the band at $3437 \mathrm{~cm}^{-1}$ which shows strongest band in SWCNTs was vanishes after addition of SWCNTs signified that SWCNTs were successfully covalently encapsulated by two layers of polymeric matrices. The carboxylic acid group may have reacted with $\mathrm{OH}$ group in the blend to form ester groups and consist broad band at $3320-3400 \mathrm{~cm}^{-1}$ was overlapping of free amine group (NH) in urethane linkage and hydroxyl group $(\mathrm{OH})$ in SWCNT-COOH.

\subsection{X-Ray Diffraction (XRD)}

Figure 3 display the X-ray diffraction of PU/PVC doped SWNTs in the range of $2 \theta=5^{\circ}$ to $70^{\circ}$. The spectra show the semicrystalline behavior and characterized by two peaks at $2 \theta=21.6^{\circ}$ and $22.3^{\circ}$. The spectra which contain SWCNTs showed much lower diffraction intensity compared to the blend and these peaks become broadened with reduced intensity refers to a reduction of the crystallinity of the blend with increase of SWCNTs contents. This change can be attributed to changing in the crosslink density of the polymer blend with increase in SWCNTs. The SWCNTs considerably affect the well short-range microstructural phases of both soft and hard segments of polymeric matrices attributed to the presence of strong interfacial interactions between components. No peaks pertaining to SWCNT appeared in the spectra indicating the complete/partial dissolution of the SWCNT in the polymer matrix.

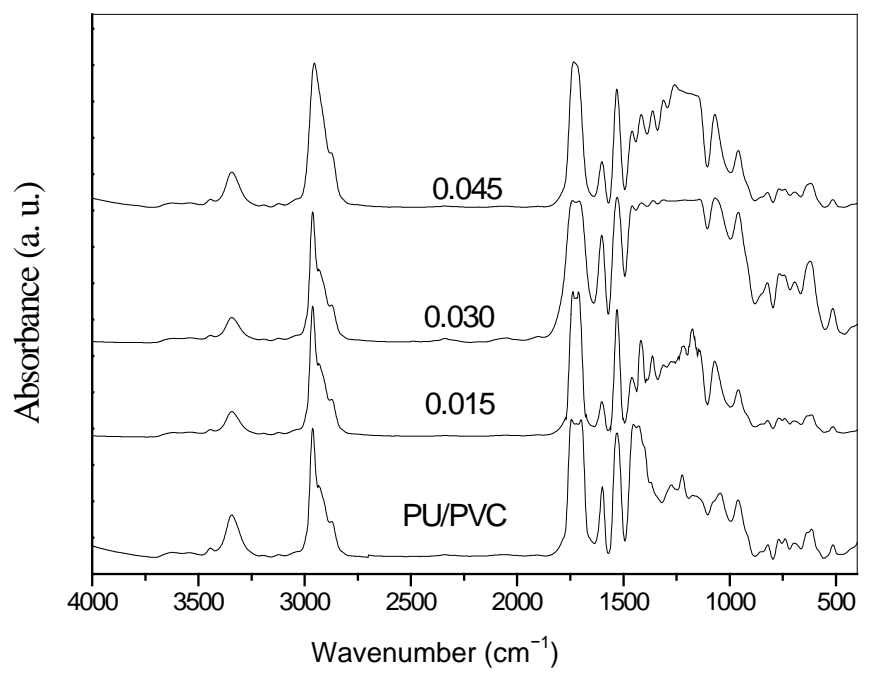

Figure 2. FT-IR spectra of PU/PVC doped SWCNT. 


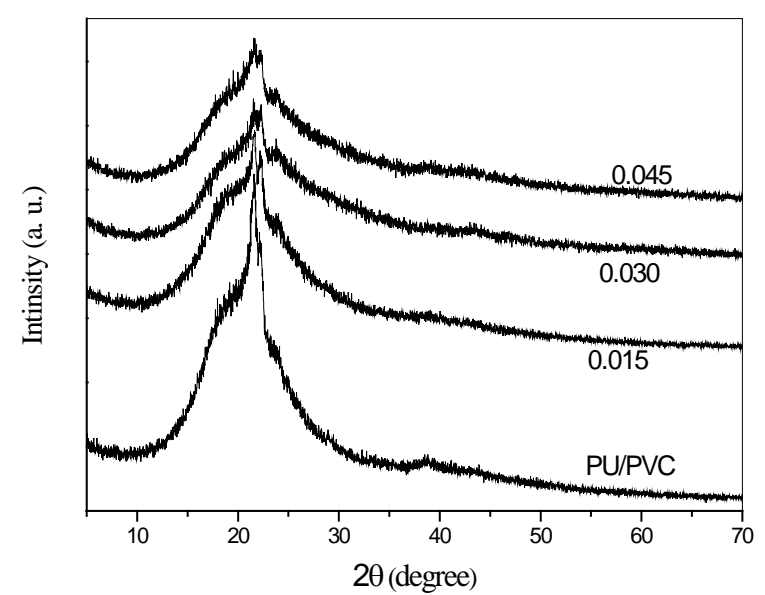

Figure 3. X-ray spectra of PU/PVC doped SWCNT.

\subsection{Ultraviolet and Visible Study}

Figure 4(a), Figure 4(b) shows UV-Vis spectra of PU/PVC doped with low content of SWCNTs $(\leq 0.045 \mathrm{wt} \%)$ in the range of $190-600 \mathrm{~nm}$. All spectra exhibit very small absorbance in the ultra-violet range from 200 to $380 \mathrm{~nm}$. The absorption band at $200 \mathrm{~nm}$ for the blend was assigned to $\mathrm{n} \rightarrow \pi^{*}$ transitions and the band at $290 \mathrm{~nm}$ was attributed to $\pi \rightarrow \pi^{*}$ transition [17]. The main absorption edge for all curves was observed at about $208 \mathrm{~nm}$ which shifted toward longer wavelengths by about $20 \mathrm{~nm}$ with increasing SWCNT content. This shift in the bands indicates interactions between the polymers chains with the nanotube surface.

The optical energy band gap $\left(E_{g}\right)$ for transitions can be determined by using the equations [18]:

$$
(\alpha h v)=C\left(h v-E_{g}\right)^{n}
$$

where $C$ is a constant and $\mathrm{n}$ is the order which characterizes the optical absorption processes. It's that can take values as: $n=1 / 2$ for indirect allowed transition, $n=1$ for nonmetallic materials, $n=3 / 2$ for direct forbidden transition, $n=2$ for direct allowed transition and $n=3$ for indirect forbidden transition [19].

The plot of $(\alpha h v)^{1 / 2}$ from Equation (1) depends on of photon energy ( $\left.h v\right)$ as shown in Figure 5 is used to calculate the indirect optical energy gap. The estimated values of indirect energy gap are recorded in Table 1 . The indirect band gap values was decreased with increase SWCNT content attributed to the formation of defects in the polymeric matrix with increase in the degree of disorder in the films. These defects produce the localized states in the optical band gap.

\subsection{Thermogravimetric Analysis (TGA)}

Figure 6 shows the TGA thermograms of PU/PVC doped with single walled carbon nanotubes from $30^{\circ} \mathrm{C}$ to $650^{\circ} \mathrm{C}$. Two major weight losses were observed in all curves. The first weight loss of pure blend was observed from $220^{\circ} \mathrm{C}$ to $350^{\circ} \mathrm{C}$ attributed to losses of vapors and gasses from the blend. The initial weight loss were observed for all 


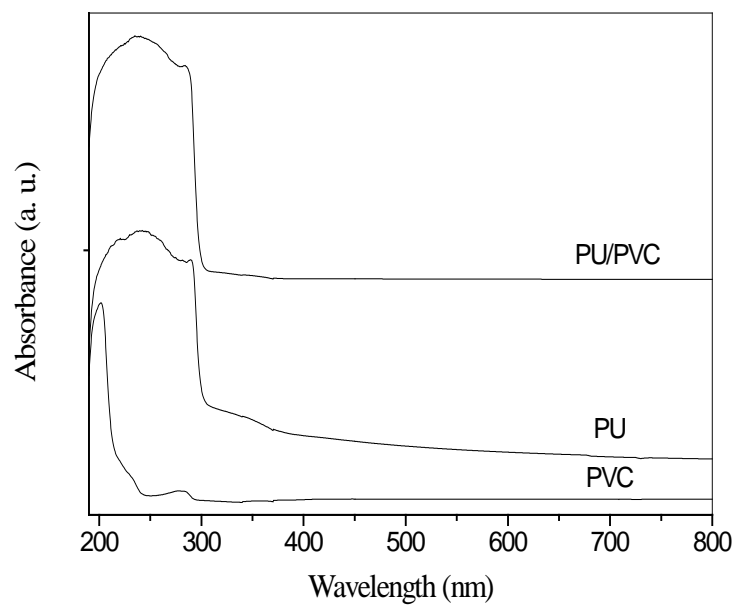

(a)

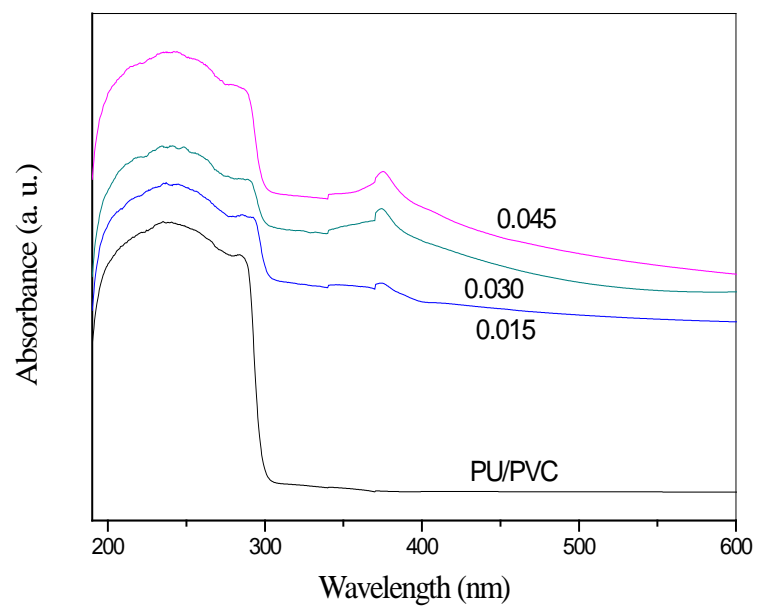

(b)

Figure 4. (a) UV-Vis spectra of pure PU, pure PVC and pure PU/PVC; (b) UV-Vis spectra of PU/PVC doped SWCNT.

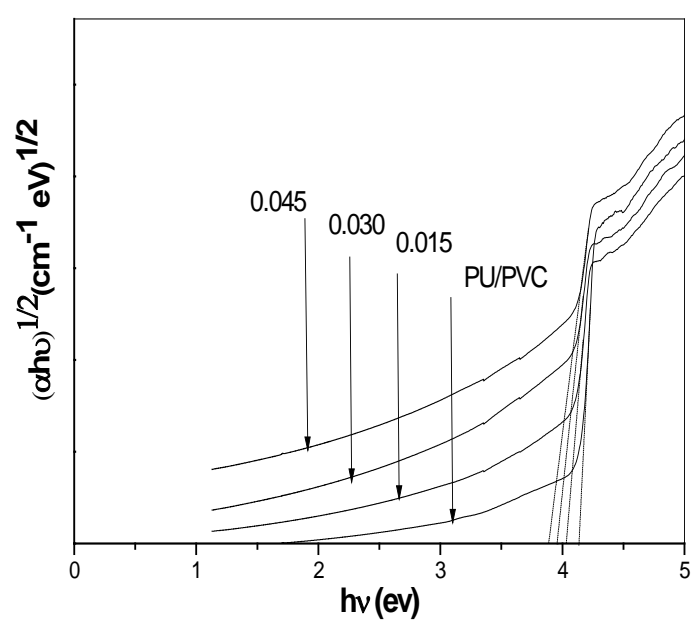

Figure 5. The relation between $(\alpha h v)^{1 / 2}$ versus $(h v)$ of PU/PVC doped SWCNT. 
Table 1. The calculated values of direct band energy and the activation energy of PU/PVC doped SWCNTs.

\begin{tabular}{cccc}
\hline SWCNTs (wt\%) & $\mathrm{E}_{\mathrm{gd}}(\mathrm{eV})$ & $\begin{array}{c}\text { Coats-Redfern method } \\
(\mathrm{KJ} / \mathrm{mol})\end{array}$ & $\begin{array}{c}\text { Broido method } \\
(\mathrm{KJ} / \mathrm{mol})\end{array}$ \\
\hline PU/PVC & 4.2 & 242 & 243 \\
0.015 & 4.1 & 220 & 224 \\
0.030 & 4.0 & 217 & 219 \\
0.045 & 3.9 & 212 & 215 \\
\hline
\end{tabular}

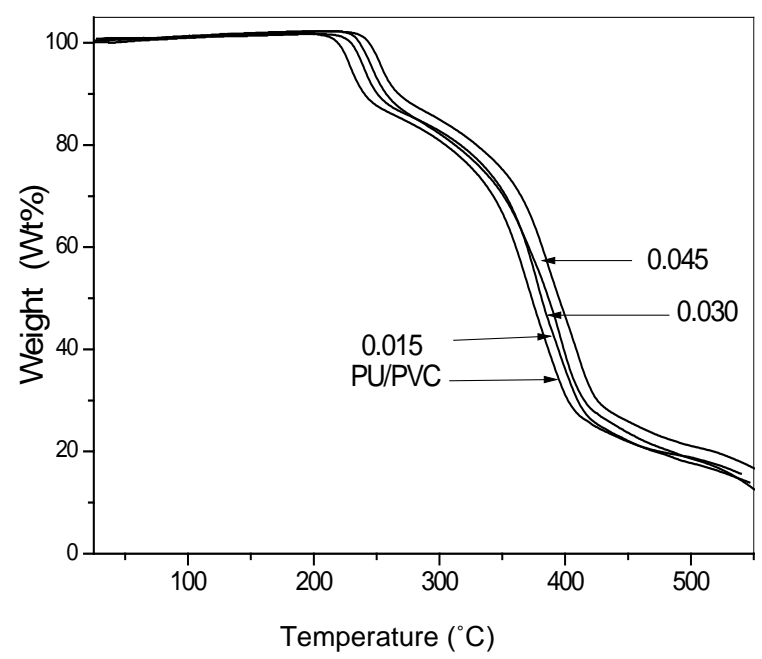

Figure 6. TGA thermograms of PU/PVC doped SWCNT.

prepared nanocomposites at lower temperatures may be attributed to the residual solvent evolution. The second weight loss from $360^{\circ} \mathrm{C}$ to $420^{\circ} \mathrm{C}$ corresponding to burning of organic phase and the thermal dehydration of inorganic particles. The weight loss at $\mathrm{t}>420^{\circ} \mathrm{C}(\approx 3 \%)$ due to degradation of large polymer chains into small fragments which subsequently undergo further decomposition forming carbonaceous matter at around $510^{\circ} \mathrm{C}$ and remains constant there after showing the plateau behavior. For doped samples, there is higher stability attributed to the combined effect of the excellent thermal stability of CNTs and their strong interfacial interactions with the polymeric matrix. It is possible that the formation of compact char of carbon nanotubes and polymer matrix during the thermal degradation is beneficial to the improvement of thermal stability of the composites. It is important to point out that the extent of interaction between SWNTs and polymer matrix with good dispersion could be responsible for a higher thermal stability of the composite system.

\subsection{Calculation of the Activation Energy}

The thermodynamics parameters of main decomposition process in the second degradation region of the present samples can be calculated using two different methods: 


\subsubsection{Coats-Redfern Method}

Coats-Redfern method is a typical integral method and can be represented in the following form [20]:

$$
\log \left[\frac{-\log (1-\alpha)}{T^{2}}\right]=\log \frac{R}{\Delta E_{a}}\left[1-\frac{2 R T}{E_{a}}\right]-0.434 \frac{E_{a}}{R T}
$$

where, $T$ is the absolute temperature in Kelvin, $E_{a}$ is the activation energy in $\mathrm{J} / \mathrm{mol}, R$ is the universal gas constant $(8.3136 \mathrm{~J} / \mathrm{mol} \mathrm{K})$, and the fraction of conversion $(\alpha)$ for a weight loss.

The plot between $\log \left[\frac{-\log (1-\alpha)}{T^{2}}\right]$ vs $\frac{1000}{T}$ of the samples, the relation give a parallel straight lines. So, the activation energies are determined from slopes of these lines as:

$$
E_{a}=2.303 R \times \text { slope }
$$

\subsubsection{Broido Method}

Broido introduce a model to evaluate the activation energy associated with second stage of decomposition using equation [21]:

$$
\ln \left[\ln \left(\frac{1}{Y}\right)\right]=\left(\frac{E_{a}}{R}\right) \frac{1}{T}+C
$$

$Y$ is given by :

$$
Y=\frac{W_{t}-W_{\infty}}{W_{i}-W_{\infty}}
$$

where, $Y$ is the fraction of the number of initial molecules not yet decomposed; $W_{t}$ is the weight at any time $t, W_{\infty}$ is the weight at infinite time (=zero) and $W_{i}$ is the initial weight. A plot between $\ln [\ln (1 / Y)]$ vs. $1 / T$ gives an excellent approximation to a straight line. The slope is related to the activation energy. The values of the activation energy $\left(E_{a}\right)$ for both methods are recorded in Table 1 . From the Table 1, the calculated values of the activation energy were decreased with increasing of SWCNTs addition indicates that SWCNTs intensively affect the polymer.

\section{Conclusion}

Nanocomposites of PU/PVC-doped SWCNTs were prepared and characterized using different techniques. The FT-IR spectra show shift and disappearance of some bands after adding SWCNTs in PU/PVC blend. It indicates a good physical entanglement between the constituents and clearly the interaction between the SWCNT and the blend. The XRD results revealed broad peaks with lower intensity in relation with pure blend, which inferred that the SWCNTs considerably affect the well short range microstructural phases of both the soft and the hard segments of the polymer matrix, resulting in strong interfacial interactions. The UV-Vis shows shift of the bands towards longer wavelength. The TGA study shows that the incorporation of SWCNTs significantly improved the thermal stability caused by the high thermal conductivity. The 
calculated values of energies gap were decreased with increasing of SWCNTs.

\section{References}

[1] Wang, C., Chen, X., Xie, H. and Cheng, R. (2011) Effects of Carbon Nanotube Diameter and Functionality on the Properties of Soy Polyol-Based Polyurethane. Composites. Part A, 42,1620 .

[2] Wu, X.L. (2010) Poly(vinyl Chloride)-Grafted Multi-Walled Carbon Nanotubes via Friedel-Crafts Alkylation. eXPRESS Polymer Letters, 4, 723-728. https://doi.org/10.3144/expresspolymlett.2010.87

[3] Soudais, Y., Moga, L., Blazek, J. and Lemort, F. (2007) Coupled DTA-TGA-FT-IR Investigation of Pyrolytic Decomposition of EVA, PVC and Cellulose. Journal of Analytical and Applied Pyrolysis, 78, 46.

[4] Haponiuk, J.T. and Balas, A. (1995) Thermal Properties of Poly(vinyl Chloride)/Polyurethane Blends. Journal of Thermal Analysis and Calorimetry, 43, 215-218.

https://doi.org/10.1007/BF02635987

[5] Kolesov, S.V., Neboilova, I.V., Steklova, A.M., Vladychina, S.V. and Minsker, K.S. (1989) Kinetics of Thermal Degradation of Poly(vinyl Chloride)-Polyurethane Blends. Polymer Science U.S.S.R., 31, 476.

[6] Malysheva, T.L., Golovan, S.V. and Starokadomsky, D.L. (2011) The Effect of Interfacial Interactions on a Structure and Properties of Polyurethane Elastomer/Poly(Vinyl Chloride) Blends. Open Journal of Organic Polymer Materials, 3, 1-7. https://doi.org/10.4236/ojopm.2011.11001

[7] Foy, J.V. and Lindt, J.T. (1987) Electrical Properties of Exfoliated-Graphite Filled Polyester Based Composites. Polymer Composites, 8, 419-426. https://doi.org/10.1002/pc.750080608

[8] Elashmawi, I.S. and Gaabour, L.H. (2015) Raman, Morphology and Electrical Behavior of Nanocomposites Based on PEO/PVDF with Multi-Walled Carbon Nanotubes. Results in Physics, 5, 105-110. https://doi.org/10.1016/j.rinp.2015.04.005

[9] Wang, Y.S.O., Gurkis, M.A. and Lindt, J.T. (1986) Electrical Properties of Exfoliated-Graphite Filled Polyethylene Composites. Polymer Composites, 7, 449-454.

[10] Haggenmueller, R., Fischer, J.E. and Winey, K.I. (2006) Single Wall Carbon Nanotube/Polyethylene Nanocomposites: Nucleating and Templating Polyethylene Crystallites. Macromolecules, 39, 2964-2971. https://doi.org/10.1021/ma0527698

[11] Haggenmueller, R., Gommans, H.H., Rinzler, A.G., Fischer, J.E. and Winey, K.I. (2000) Aligned Single-Wall Carbon Nanotubes in Composites by Melt Processing Methods. Chemical Physics Letters, 330, 219-225. https://doi.org/10.1016/S0009-2614(00)01013-7

[12] Hou, H., Ge, J.J., Zeng, J., Li, Q., Reneker, D.H. and Greiner, A. (2005) Electrospun Polyacrylonitrile Nanofibers Containing a High Concentration of Well-Aligned Multiwall Carbon Nanotubes. Chemistry of Materials, 17, 967-973. https://doi.org/10.1021/cm0484955

[13] Barick, A.K. and Tripathy, D.K. (2010) Effect of Nanofiber on Material Properties of vaporGrown Carbon Nanofiber Reinforced Thermoplastic Polyurethane (TPU/CNF) Nanocomposites Prepared by Melt Compounding. Composites: Part A, 41, 1471-1482. https://doi.org/10.1016/j.compositesa.2010.06.009

[14] Travati, G., Sanches, E.A., Neto, S.C., Mascarenhas, Y.P. and Chierice, G.O. (2010) Characterization of Polyurethane Resins by FTIR, TGA, and XRD. Journal of Applied Polymer Science, 115, 263-268. https://doi.org/10.1002/app.31096

[15] Beltran, M., Garcia, J.C. and Marcilla, A. (1997) Infrared Spectral Changes in PVC and 
Plasticized PVC during Gelation and Fusion. European Polymer Journal, 33, 453-462. https://doi.org/10.1016/S0014-3057(96)00213-3

[16] Ramesh, S. and Yi, L.J. (2009) FTIR Spectra of Plasticized High Molecular Weight PVC$\mathrm{LiCF}_{3} \mathrm{SO}_{3}$ Electrolytes. Ionic, 15, 413-420. https://doi.org/10.1007/s11581-008-0279-z

[17] Elashmawi, I.S. and Hakeem, N.A. (2008) PMMA Addition on Characterization and morphology of the PVDF. Polymer Engineering \& Science, 48, 895-901. https://doi.org/10.1002/pen.21032

[18] Kramadhati, S. and Thyagarajan, K. (2013) Optical Properties of Pure and Doped (Kno3 \& Mgcl2) Polyvinyl Alcohol Polymer Thin Films. International Journal of Engineering Research and Development, 6, 15-18.

[19] Ramirez, R.J., Arellano, C., Varia, J.C. and Martinez, S.S. (2015) Visible Light-Induced Photocatalytic Elimination of Organic Pollutants by $\mathrm{TiO}_{2}$ : A Review. Current Organic Chemistry, 19, 540-555. https://doi.org/10.2174/138527281906150417094736

[20] Coats, A.W. and Redfern, J.P. (1964) Kinetic Parameters from Thermogravimetric Data. Nature, 201, 68-69. https://doi.org/10.1038/201068a0

[21] Broido, A. (1969) A Simple, Sensitive Graphical Method of Treating Thermogravimetric Analysis Data. Journal of Polymer Science Part A, 7, 1761-1773.

https://doi.org/10.1002/pol.1969.160071012

Submit or recommend next manuscript to SCIRP and we will provide best service for you:

Accepting pre-submission inquiries through Email, Facebook, LinkedIn, Twitter, etc. A wide selection of journals (inclusive of 9 subjects, more than 200 journals)

Providing 24-hour high-quality service

User-friendly online submission system

Fair and swift peer-review system

Efficient typesetting and proofreading procedure

Display of the result of downloads and visits, as well as the number of cited articles

Maximum dissemination of your research work

Submit your manuscript at: http://papersubmission.scirp.org/

Or contactopj@scirp.org 